\title{
KINERJA KEUANGAN PADA PERUSAHAAN UMUM DAERAH AIR MINUM TIRTA MANGUTAMA KABUPATEN BADUNG
}

\author{
Ni Luh Putu Aryani \\ Luh Kade Datrini, \\ Ida Bagus Made Putra Manuaba \\ Fakultas Ekonomi dan Bisnis Universitas Warmadewa, Denpasar, Bali-Indonesia \\ E-mail: Putuaryani@gmail.com
}

\begin{abstract}
ABSTRAKSI
PDAM merupakan badan usaha yang harus menjalankan dua fungsi sekaligus, yaitu sebagai social oriented dan profit oriented. Dalam menjalankan perusahaan perlu dilakukan evaluasi atas kinerja yang telah dilakukan. Sebagai alat evaluasi dan perencanaan program kedepan perlu dilakukan analisis keuangan untuk memperoleh laba yang optimal, dengan laba tersebut maka perusahaan akan dapat mempertahankan keberlangsungan hidup perusahaan. Penelitian dengan judul "Pengaruh Rasio Likuiditas, Solvabilitas, Dan Aktivitas Terhadap Kinerja Keuangan Pada Perusahaan Umum Daerah Air Minum Tirta Mangutama Kabupaten Badung",memiliki rumusan masalah apakah Rasio Likuiditas, Solvabilitas, Dan Aktivitas berpengaruh terhadap kinerja keuangan pada Perusahaan Umum Daerah Air Minum Tirta Mangutama Kabupaten Badung . Tujuan penelitian ini adalah untuk mengetahui pengaruh Rasio Likuiditas, Solvabilitas, Dan Aktivitas terhadap kinerja keuangan pada Perusahaan Umum Daerah Air Minum Tirta Mangutama Kabupaten Badung. Data yang digunakan dalam penelitian ini berupa laporan keuangan tahun 2015 sampai 2019. Penelitian ini menggunakan metode analisis regresi linier berganda yang diolah dengan alat bantu aplikasi SPSS. vHasil penelitian ini menunjukkan bahwa Likuiditas yang dihitung menggunakan (current ratio) berpengaruh positif terhadap kinerja keuangan. Hasil tersebut sejalan dengan hasil penelitian yang sudah dilakukan oleh Mutiara (2018) yang menyatakan bahwa rasio likuiditas yang dinyatakan dengan current ratio berpengaruh positif terhadap kinerja keuangan (ROI). Solvabilitas yang dihitung menggunakan (debt to equity ratio) berpengaruh negatif terhadap kinerja keuangan. Hasil penelitian ini sejalan dengan hasil penelitian yang telah dilakukan oleh Fibriyanti (2018) yang menyatakan bahwa rasio solvabilitas (debt to equity ratio) berpengaruh negative terhadap kinerja keuangan (return on investment). Aktivitas yang dihitung menggunakan (total assets turnover ) berpengaruh positif terhadap kinerja keuangan. Hasil penelitian ini sejalan dengan hasil penelitian yang telah dilakukan oleh Esthirahayu et al. (2014) dan Al-Faruqy (2016) yang menyatakan bahwa rasio aktivitas (total assets turnover) berpengaruh terhadap kinerja keuangan (return on investment).
\end{abstract}

Kata Kunci: Rasio Likuiditas;Solvabilitas; Dan Aktivitas; Kinerja Keuangan 


\section{PENDAHULUAN}

Dalam sektor penyediaan dan pendistribusian air minum pemerintah mendirikan Perusahaan Daerah Air Minum (PDAM), PDAM ini bertujuan untuk menyediakan air bersih bagi masyarakat setempat yang struktur organisasinya berinduk pada pemerintah daerah. PDAM merupakan badan usaha yang harus menjalankan dua fungsi sekaligus, yaitu sebagai social oriented dan profit oriented. Social oriented adalah pelayanan yang baik terhadap masyarakat dalam penyediaan air

\section{TINJAUAN PUSTAKA.}

\section{Rasio Likuiditas.}

Rasio likuiditas merupakan rasio yang membandingkan antara hutang jangka pendek dengan aktiva lancar yang tersedia untuk dapat memenuhi kewajiban perusaha

\section{Rasio Solvabilitas.}

Rasio solvabilitas ini menggambarkan ketersediaan dana yang digunakan oleh perusahaan dalam membayar seluruh kewajiban.

\section{Rasio Aktivitas.}

rasio aktivitas dapat digunakan untuk mengukur kinerja

manajemen pada tingkat efisiensi dalam mengelola adan memanfaatkan sumber daya yang ada.

\section{Kinerja Keuangan}

Kinerja perusahaan merupakan suatu indikator untuk menilai posisi perusahaan dalam periode bersih, sedangkan profit oriented adalah tujuan untuk menghasilkan laba sebagai dana untuk beroperasi dan sebagai sumber penerimaan daerah. Maka sudah menjadi keharusan agar di dalamnya menjalankan kedua fungsi tersebut (Widyanto, 2012: 1). Dalam menjalankan perusahaan perlu dilakukan evaluasi atas kinerja yang telah dilakukan oleh seluruh elemen perusahaan. Sebagai alat evaluasi dan perencanaan program kedepan perlu untuk dilakukannya analisis kinerja keuangan.

tertentu, salah satunya dengan menilai kinerja keuangan perusahaan

\section{Laporan Keuangan}

Prastowo (2015:1), menyatakan bahwa laporan keuangan adalah obyek dari setiap analisis terhadap laporan keuangan

\section{A. HIPOTESIS.}

1. Pengaruh Rasio Likuiditas Terhadap Kinerja Keuangan.

Rasio likuiditas pada penelitian ini di ukur dengan current ratio (rasio lancar), dimana current ratio digunakan sebagai indikator dalam mengukur kemampuan perusahaan untuk memenuhi kewajiban jangka pendek yang segera jatuh tempo. Perusahaan yang menunjukkan hasil current ratio yang tinggi menandakan perusahaan tersebut mampu untuk membayar keseluruhan kewajiban jangka pendeknya dengan tepat waktu. Informasi yang didapatkan dari hasil penelitian terdahulu dan teori di atas, maka hipotesis yang diajukan sebagai berikut: $\mathrm{H}_{1}$ : Rasio likuiditas 
berpengaruh terhadap kinerja keuangan (Dr.

Kasmir. (2015).Analisis

Laporan

Keuangan.Jakarta.PT.

RajaGrafindo

Persada).

\section{Pengaruh Rasio Solvabilitas Terhadap Kinerja Keuangan.}

Rasio solvabilitas pada penelitian ini di ukur dengan debt to equity ratio, dimana debt to equity ratio digunakan sebagai indikator untuk mengukur sejauh mana perusahaan membiayai keseluruhan asetnya dengan mengandalkan hutang dengan menggunakan modal sendiri (pemilik). Informasi dari hasil penelitian terdahulu dan teori di atas, maka hipotesis yang diajukan sebagai berikut: $\mathrm{H}_{2}$ : Rasio solvabilitas berpengaruh terhadap kinerja keuangan (Dr. Kasmir. (2015).Analisis Laporan Keuangan.Jakarta.PT. RajaGrafindo Persada)

\section{Pengaruh Rasio Solvabilitas Terhadap Kinerja Keuangan}

Menurut Dr. Kasmir (2015) Total asset turnover merupakan rasio yang digunakan untuk mengukur perputaran semua aktiva yang dimiliki perusahaan dan mengukur berapa jumlah penjualan yang diperoleh dari setiap rupiah aktiva. $\mathrm{H}_{3}$ : Rasio aktivitas berpengaruh terhadap kinerja keuangan (Dr. Kasmir. (2015).Analisis

Laporan

Keuangan.Jakarta.PT.

RajaGrafindo

Persada).

\section{METODE PENELITIAN}

A. Tempat/Lokasi dan Obyek Penelitian.
Penelitian dilakukan pada Perusahaan Umum Daerah Air Minum Tirta Mangutama Badung yang beralamat di Jalan Bedahulu No.3, Dauh Puri Kaja, Kec. Denpasar Utara, Kota Denpasar, Bali 80111.

Objek penelitian yang akan diteliti yaitu mengenai kinerja keuangan melalui laporan keuangan dari tahun 2015-2019 pada Perusahaan Umum Daerah Air Minum Tirta Mangutama Badung.

\section{B. Populasi dan Metoda Penentuan}

\section{Sampel.}

Populasi dari objek penelitian ini yaitu dokumen laporan keuangan Perusahaan Daerah Air Minum (PDAM) Tirta Mangutama Kabupaten Badung periode 2017-2019. Pada penelitian ini tidak menggunakan metode penentuan sampel dikarenakan dalam penelitian ini penulis hanya berfokus pada satu obyek populasi yang digunakan yaitu meneliti bagaimana pengaruh rasio likuiditas (CR), rasio solvabilitas (DER), dan rasio aktivitas (TATO) terhadap kinerja keuangan (ROI) Perusahaan Daerah Air Minum (PDAM) Tirta Mangutama Kabupaten Badung.

\section{Identifikasi Variabel.}

Pada penelitian ini penulis menggunakan variabel dependen (variabel terikat) dan variabel independen (variabel bebas). Menurut Kadir (2015:8), menyatakan bahwa variabel dependen merupakan variabel yang dipengaruhi variabel lain dalam kondisi ini dipengaruhi oleh variabel independen (variabel bebas), sedangkan variabel independen adalah variabel yang mempengaruhi variabel lain 
dalam kondisi ini mempengaruhi variabel dependen.

\section{Definisi Operasional Variabel.}

\section{Variabel Dependen (Y)}

Variabel dependen (variabel terikat) dalam penelitian ini adalah kinerja keuangan (Y), sehingga dalam penelitian ini kinerja keuangan diukur dengan menggunakan Return On Investment (ROI), Pengukuran variabel ini menggunakan rumus sebagai berikut:

\section{Return On Investment}

$$
=\frac{\text { Laba Setelah Pajak }}{\text { Total Aset }}
$$

\section{Variabel Independen (X)}

a. Rasio Likuiditas

Pada penelitian ini rasio likuiditas diukur dengan menggunakan current ratio, dimana rasio ini digunakan untuk mengukur sejauh mana kemampuan perusahaan menggunakan aktiva lancarnya untuk memenuhi dan membayar kewajiban lancarnya yang akan jatuh tempo. Adapun rasio ini dihitung dengan rumus sebagi berikut:

$$
\begin{aligned}
& \text { Current Ratio } \\
& =\frac{\text { Aset Lancar }}{\text { Hutang Lancar }}
\end{aligned}
$$

b. Rasio Solvabilitas
Rasio solvabilitas digambarkan untuk mengukur sejauh mana aktiva perusahaan dibiayai dengan mengandalkan hutang (pinjaman) dibandingkan dengan total ekuitas, semakin besar hasil presentase dari rasio solvabilitas menunjukkan risiko investasi yang semakin besar dan sebaliknya. Rasio solvabilitas dalam penelitian ini diukur dengan Debt to Equity Ratio (DER) yang dihitung dengan rumus sebagai berikut:

Debt to Equity Rati $=\frac{\text { Total Hutang }}{\text { Total Ekuitas }}$

c. Rasio Aktivitas

Rasio aktivitas digambarkan untuk mengukur efektivitas perputaran total aset yang dimiliki perusahaan untuk menciptakan laba dari hasil penjualan dan investasi, semakin banyak (kali) perputaran aset perusahaan menunjukkan semakin efisiensi perusahaan dalam mengelola dan memanfaatkan sumber daya untuk memperoleh laba. Rasio aktivitas dalam penelitian ini diukur dengan menggunakan Total Assets Turnover (TATO) yang dihitung dengan rumus sebagai berikut:

$$
\text { Total Assets Turnover }=\frac{\text { Penjualan }}{\text { Total Aset }}
$$


IV. Hasil Analsis dan Pembasan.

A. Analisis Regresi Linier Berganda

Tabel 1.

\begin{tabular}{|c|c|c|c|c|c|c|}
\hline \multicolumn{7}{|c|}{ Coefficients $^{\mathrm{a}}$} \\
\hline & & \multicolumn{2}{|c|}{$\begin{array}{c}\text { Unstandardized } \\
\text { Coefficients }\end{array}$} & \multirow{2}{*}{$\begin{array}{c}\text { Standardized } \\
\text { Coefficients }\end{array}$} & \multirow[b]{2}{*}{$\mathrm{T}$} & \multirow[b]{2}{*}{ Sig. } \\
\hline \multicolumn{2}{|c|}{ Model } & B & Std. Error & & & \\
\hline \multirow[t]{4}{*}{1} & (Constant) & 1,012 & 0,030 & & 1,411 & 0,046 \\
\hline & CR & 0,058 & 0,006 & 0,005 & 1,031 & 0,016 \\
\hline & DER & $-0,011$ & 0,051 & $-0,033$ & $-1,209$ & 0,037 \\
\hline & TATO & 0,132 & 0,028 & 0,783 & 4,635 & 0,000 \\
\hline
\end{tabular}

a. Dependent Variable: ROI

Hasil Analisis Regresi Linier Berganda

Sumber : Data Diolah (2020)

Uji asumsi klasik menunjukkan bahwa dia telah mendekati sebaran normal , tidak ada multikolinearitas dan tidak terjadi heterodkedastisitas pada model regresi maka data-data tersebut dapat dilakukan analisis. Teknik analisis yang digunakan yaitu teknik analisis linier

berganda. Hasil analisis data tersbut disajikan dalam tabel 2 diatas. Berdasarkan tabel diatas diperoleh model regresi linier berganda yang terbentuk pada penelitian ini adalah sebagai berikut:

ROI $=1.012+0.058$ CR -0.011 DER +0.132

\section{TATO}

Berdasarkan persamaan tersebut, maka variabel Current Ratio, Debt of Equity Ratio, dan Total Asset Turnover berpengaruh terhadap Return On Invesment pada Perumda Tirta Mangutama Kabupaten Badung.

1. Uji Goodness Of Fit (Uji F)Uji statistik F bertujuan untuk mengetahui kelayakan suatu model yang digunakan dalam penelitian ini agar bisa digunakan untuk tahap pengujian selanjutnya. Untuk menguji kelayakan model dapat menggunakan uji statistik $\mathrm{F}$ dengan tingkat signifikansi $\alpha=0,05$, 
Tabel 2.

Hasil Uji Kelayakan Model (Uji F)

\begin{tabular}{|c|c|c|c|c|c|c|}
\hline \multicolumn{7}{|c|}{ ANOVA $^{\mathrm{a}}$} \\
\hline \multicolumn{2}{|c|}{ Model } & $\begin{array}{l}\text { Sum of } \\
\text { Squares }\end{array}$ & $\mathrm{df}$ & $\begin{array}{l}\text { Mean } \\
\text { Square }\end{array}$ & $\mathrm{F}$ & Sig. \\
\hline \multirow[t]{3}{*}{1} & Regression & 0,017 & 3 & 0,006 & 8,613 & $0,001^{\mathrm{b}}$ \\
\hline & Residual & 0,011 & 16 & 0,001 & & \\
\hline & Total & 0,028 & 19 & & & \\
\hline \multicolumn{7}{|c|}{ a. Dependent Variable: ROI } \\
\hline \multicolumn{7}{|c|}{ b. Predictors: (Constant), TATO, DER, CR } \\
\hline
\end{tabular}

Sumber: data diolah (2020)

Pada tabel 3. diatas, diketahui nilai signifikansi adalah sebesar 0,001 atau lebih kecil dari 0,05. Maka sebagaimana dasar pengambilan keputusan dalam uji $\mathrm{F}$ dapat disimpulkan bahwa penelitian dikatakan layak untuk tahap pengujian

berikutnya atau dengan kata lain rasio likuiditas, rasio solvabilitas, dan rasioaktivitas secara simultan berpengaruh terhadap kinerja keuangan

\section{Uji Koefisien Determinasi $\left(\mathbf{R}^{\mathbf{2}}\right)$ Nilai} koefisien yang diperoleh adalah sebesar 0.546 atau 54,6\%. Hal ini mengindikasikan bahwa Kinerja Keuangan dipengaruhi 54,6\% oleh variabel Current Ratio (CR), Debt to Equity Ratio (DER) , dan Total Assets Turnover (TATO), sisanya sebesar $45,4 \%$ dipengaruhi oleh variabel lain yang tidak dimasukkan ke dalam penelitian.

\section{Koefisien Korelasi (R)}

Besarnya nilai koefisien korelasi (R) diperoleh hasil sebesar 0,786. Hal ini menunjukkan bahwa terdapat hubungan yang kuat antara Current Ratio (CR), Debt to Equity Ratio (DER), dan Total Assets Turnover (TATO) terhadap Return On Investment (ROI)

\section{Pengujian Hipotesis (Uji t)}

Pengujian hipotesis dengan menggunakan uji $t$ merupakan suatu pengujian yang digunakan untuk mengetahui apakah secara parsial variabel independen rasio likuiditas (CR), rasio solvabilitas (DER) dan rasio aktivitas (TATO) berpengaruh terhadap variabel dependen kinerja keuangan (ROI).

\section{B. PEMBAHASAN.}

1. Pengaruh Rasio Likuiditas (CR) terhadap Kinerja Keuangan (ROI).

Berdasarkan hasil Uji t Rasio Likuiditas (CR) setelah diuji secara parsial dengan menggunakan uji t, diperoleh koefisien regresi bernilai positif sebesar 0,058 dengan signifikansi sebesar $0,016<0,05$.

\section{Pengaruh Rasio Solvabilitas (DER) terhadap Kinerja Keuangan (ROI).}


Berdasarkan hasil Uji $t$ pada Rasio Solvabilitas (DER) setelah diuji secara parsial dengan menggunakan uji t, diperoleh koefisien regresi bernilai negatif sebesar 0,011 dengan signifikansi sebesar $0,037<0,05$.

\section{Pengaruh Rasio Aktivitas (TATO) terhadap Kinerja Keuangan (ROI)}

Berdasarkan hasil Uji $\mathrm{t}$ pada Rasio Aktivitas (TATO) setelah diuji secara parsial dengan menggunakan uji $t$, diperoleh koefisien regresi bernilai positif sebesar 0,132 dengan signifikansi sebesar $0,000<0,05$.

\section{PENUTUP}

\section{A. Simpulan}

Perumda Tirta Mangutama Kabupaten Badung Tahun 2015-2019. Berdasarkan informasi dari hasil penelitian yang telah dilakukan, maka dapat disimpulkan sebagai berikut:

1. Rasio likuiditas yang dihitung dengan current ratio berpengaruh positif terhadap kinerja keuangan Perumda Tirta Mangutama Kabupaten Badung Tahun 2015-2019.

2. Rasio solvabilitas yang dihitung dengan debt to equity ratio berpengaruh negatif terhadap kinerja keuangan Perumda Tira Mangutama Kabupaten Badung Tahun 2015-2019.

3. Rasio aktivitas yang dihitung dengan total assets turnover berpengaruh positif terhadap kinerja keuangan Perumda Tira
Mangutama Kabupaten Badung Tahun 2015-2019.

\section{B. Saran}

Berdasarkan hasil dan analisis dan simpulan, maka saran yang dapat disampaikan yaitu sebagai berikut:

1. Perumda Tira Mangutama Kabupaten Badung kiranya dapat meningkatkan sekaligus mempertahankan apa yang telah dicapai sekarang ini Dalam hal ini perusahaan harus mampu menyeimbangkan antara. piutang dan penjualan air per harinya

2. Bagi selanjutnya diharapkan dapat menambah jumlah variabel, sampel dan periode penelitian agar dapat mengembangkan faktor-faktor lain yang mempunyai pengaruh terhadap kinerja keuangan perusahaan.

\section{DAFTAR PUSTAKA}

Dr. Kasmir. (2015).Analisis Laporan Keuangan.Jakarta.PT. RajaGrafindo Persada.

Chaidir dan Mira Pitriana. (2017). FaktorFaktor Pengaruh Return On Investment. JIMFE (Jurnal Ilmiah Manajemen Fakultas Ekonomi) Volume 3 No. 2 . Hal 60-69.

Al-Faruqy, Ahmad Fanny (2016). Pengaruh Current Ratio, Debt To Equity Ratio Dan Total Asset Turn Over Terhadap Return On Investment (Studi Pada Perusahaan Sektor Manufaktur Yang Terdaftar Di JII Tahun 2011-2014) [Skripsi]. Bandung (ID): Universitas Islam Bandung. 